\title{
Diagnostyka i monitorowanie pracy mikroprocesorowo sterowanego bloku zasilania wzbudzenia silnika synchronicznego
}

\begin{abstract}
$W$ artykule przedstawiono blok zasilania wzbudzenia silników synchronicznych $z$ mikroprocesorowym układem sterowania. Omówiono podstawy teoretyczne regulacji mocy biernej za pomoca silnika synchronicznego oraz wpływ obciażenia na dopuszczalny obszar pracy. Przedstawiono możliwości sterowania silnikiem przez system mikroprocesorowy opracowanego urzadzenia podczas rozruchu asynchronicznego i pracy synchronicznej. Zaprezentowano możliwości monitorowania i rejestracji stanu pracy napędu pozwalające na analizę sekwencji zdarzeń w przypadku wystąienia stanów awaryjnych. Przedstawiono dedykowane oprogramowanie diagnostyczno-serwisowe. Omówiono wybrane funkcje diagnostyczne.
\end{abstract}

Słowa kluczowe: silnik synchroniczny, sterowanie pradem wzbudzenia, regulator mocy biernej, sterowanie mikroprocesorowe, zdalne sterowanie i monitorowanie

\section{WSTĘP}

Silniki synchroniczne dużej mocy wykorzystuje się w przemyśle do napędu urządzeń niewymagających regulacji prędkości obrotowej. Typowym zastosowaniem są napędy wentylatorów głównych przewietrzania kopalń głębinowych, napędy sprężarek czy wciąż jeszcze obecne w przemyśle napędy przetwornic układów Leonarda.

Jednym z podstawowych zagadnień eksploatacyjnych jest rozruch silnika. W przypadku silników jawnobiegunowych wykonuje się go zazwyczaj jako rozruch asynchroniczny bezpośredni lub $\mathrm{z}$ dławikiem rozruchowym. Procedura rozruchowa wymaga odpowiedniej sekwencji działań zgodnie $\mathrm{z}$ aktualnym stanem napędu [3, 5, 9, 13, 21, 22]. Nieudana procedura rozruchu może doprowadzić do utknięcia silnika na prędkości podsynchronicznej, długotrwałej pracy z prądem większym od znamionowego, pulsacją momentu elektromagnetycznego i oscylacji prędkości obrotowej skutkujących znacznymi przeciążeniami mechanicznymi na wale silnika i przyspieszonym zużyciem łożysk. Po nieskutecznym rozruchu kolejna próba możliwa jest po zatrzymaniu wału silnika. W układach napędowych o dużych momentach bezwładności czasy wybiegu mogą wynosić kilkanaście, a nawet kilkadziesiąt minut. Prądy rozruchowe kilku- krotnie przekraczają wartości prądów znamionowych, powodując znaczne nagrzewanie uzwojeń silnika. Z tego względu należy ograniczyć liczbę prób rozruchu w określonym przedziale czasu.

Niedociążone silniki synchroniczne często wykorzystuje się jako regulowane kompensatory mocy biernej podstawowej harmonicznej, zarówno lokalnie, jak $\mathrm{i} w$ układach $\mathrm{z}$ nadrzędnym zadawaniem mocy biernej [4, 6, 11, 12]. Regulacja mocy biernej odbywa się poprzez zmianę prądu w uzwojeniu wzbudzenia silnika podczas pracy synchronicznej $[1,8]$. Praca synchroniczna możliwa jest tylko w ograniczonym zakresie kąta mocy. Po przekroczeniu dopuszczalnego kąta mocy silnik wypada $\mathrm{z}$ synchronizmu $[2,12,18]$ i powinien zostać wyłączony awaryjnie.

Moc czynna $P$ pobierana przez silnik w stanie pracy synchronicznej opisana jest zależnością $[2,18]$

$$
P=m\left(\frac{U_{f} E_{w}}{X_{d}} \sin \vartheta+\frac{1}{2} U_{f}^{2}\left(\frac{1}{X_{q}}-\frac{1}{X_{d}}\right) \sin (2 \vartheta)\right)
$$

gdzie:

$m$ - liczba faz,

$U_{f}$ - napięcie fazowe,

$X_{d}$ - reaktancja rozproszenia w osi $d$,

$X_{q}$ - reaktancja rozproszenia w osi $q$,

$\vartheta$ - kąt mocy,

$E_{w}$ - siła elektromotoryczna indukowana w uzwojeniu wzbudzenia. 
Przy założeniu liniowości charakterystyki magnesowania siła elektromotoryczna indukowana w uzwojeniu wzbudzenia zależna jest od prądu wzbudzenia, zgodnie $\mathrm{z}$ równaniem:

$$
E_{w}=\frac{I_{w}}{k_{w}}
$$

gdzie:

$I_{w}$ - prąd wzbudzenia,

$k_{w}$ - stała związana z konstrukcją silnika.

Z zależności (1) i (2) wynika, że wpływ na kąt mocy ma obciążenie silnika mocą czynną (proporcjonalną do momentu obciążenia), wartość napięcia zasilania oraz wartość prądu wzbudzenia.

Prądy w osiach $d$ i $q$ zależne są od kąta mocy $\vartheta$ oraz siły elektromotorycznej $E_{w}$ związanej z prądem wzbudzenia zgodnie z równaniami:

$$
\begin{gathered}
I_{d}=\frac{E_{w}-U_{f} \cos \vartheta}{X_{d}} \\
I_{q}=\frac{U_{f} \sin \vartheta}{X_{q}}
\end{gathered}
$$

Prąd stojana $I$ maszyny można wyznaczyć z zależności:

$$
I=\sqrt{I_{d}^{2}+I_{q}^{2}}
$$

przy czym składowa czynna prądu $I_{P}$ ma wartość:

$$
I_{P}=\frac{P}{3 U_{f}}
$$

Stąd moc bierną silnika $Q$ można zapisać w postaci:

$$
Q= \begin{cases}-3 U_{f} \sqrt{I^{2}-I_{P}^{2}} & \text { dla } \vartheta<\vartheta_{0} \\ 3 U_{f} \sqrt{I^{2}-I_{P}^{2}} & \text { dla } \vartheta \geq \vartheta_{0}\end{cases}
$$

gdzie $\vartheta_{0}-$ kąt mocy przy pracy z $\cos \varphi=1$ przy założeniu, że znak dodatni mocy biernej oznacza pobieranie przez silnik mocy biernej indukcyjnej, a znak ujemny zwrot mocy biernej indukcyjnej do sieci (pobieranie mocy biernej pojemnościowej). Na rysunku 1 przedstawiono typowe charakterystyki mocy biernej w zależności od prądu wzbudzenia z zaznaczonym ograniczeniem wynikającym z wartości znamionowej prądu wzbudzenia.

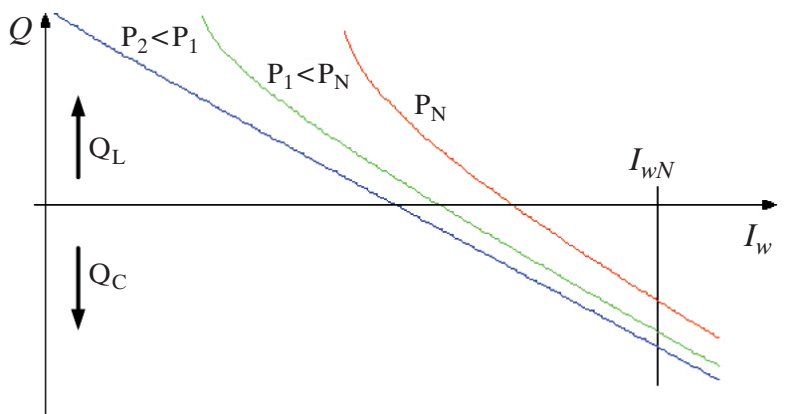

Rys. 1. Zależność mocy biernej silnika od pradu zbudzenia dla różnych wartości obciażenia moca czynna

Nadążna kompensacja mocy biernej z wykorzystaniem silnika synchronicznego może prowadzić do zmian kąta mocy przy niezmienionym momencie obciążenia. Na rysunku 2 przedstawiono typowe charakterystyki kąta mocy w zależności od prądu wzbudzenia.

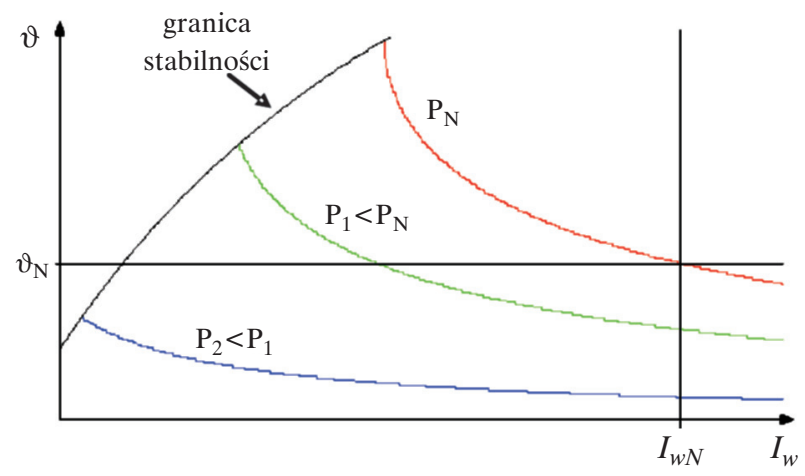

Rys. 2. Zależność kąta mocy od prądu zbudzenia dla różnych wartości obciążenia mocą czynna

Jak można zauważyć na rysunku 2, możliwa jest praca niedociążonego silnika $\mathrm{z}$ kątem mocy większym od znamionowego. Jednak przekroczenie granicy stabilności statycznej prowadzi do wypadnięcia silnika z synchronizmu i wyłączenia napędu przez układy zabezpieczeń.

Jedną z najczęściej wykorzystywanych charakterystyk opisujących stan pracy silnika synchronicznego są krzywe Mordeya, zwane także ze względu na swój kształt krzywymi V. Krzywe te można wyznaczyć analitycznie na podstawie parametrów dostępnych na tabliczce znamionowej silnika oraz wartości reaktancji synchronicznych $X_{d}$ i $X_{q}$. Przyjęcie do obliczeń właściwych wartości reaktancji $X_{d}$ i $X_{q}$ jest niezbędne do prawidłowego określenia zakresu regulacji prądu 
wzbudzenia w zależności od obciążenia silnika moca czynną, zapewniającego stabilną pracę w stanie synchronicznym. Na rysunku 3 przedstawiono typowy kształt krzywych Mordeya z zaznaczonym dopuszczalnym obszarem pracy silnika.

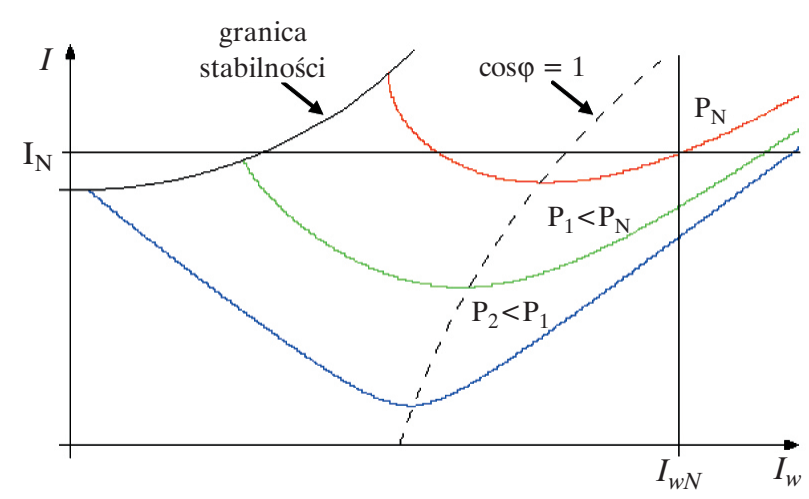

Rys. 3. Krzywe Mordeya z zaznaczonym dopuszczalnym obszarem pracy silnika

Aby zapewnić stabilną pracę w stanie synchronicznym, należy odpowiednio sterować prądem wzbudzenia, uwzględniając wpływ momentu obciążenia, napięcia zasilania, zadanej wartości mocy biernej, a także ograniczenia związane $\mathrm{z}$ wartościami znamionowymi prądu stojana i wzbudzenia, utrzymując jednocześnie kąt mocy w dopuszczalnym zakresie $[1,2,12,15,18]$.

\section{MIKROPROCESOROWY BLOK ZASILANIA WZBUDZENIA SILNIKA SYNCHRONICZNEGO}

Na rysunku 4 przedstawiono schemat bloku zasilania wzbudzenia o sterowaniu mikroprocesorowym przeznaczony do współpracy z silnikami synchronicznymi dużej mocy zasilanymi napięciem $6 \mathrm{kV}$ o znamionowych prądach wzbudzenia do $400 \mathrm{~A}[5,8]$.
Urządzenie zawiera przekształtnik tyrystorowy oraz tranzystorowy układ kluczowania rezystora rozruchowego, nadzorowane przez układ mikroprocesorowy.

Klucze tranzystorowe w obwodzie rezystora rozruchowego umożliwiają przepływ dwukierunkowego prądu indukowanego w uzwojeniu wzbudzenia podczas rozruchu asynchronicznego silnika. Bezstycznikowy układ wzbudzenia pozwala na zwiększenie niezawodności i trwałości urządzenia.

Oprogramowanie urządzenia pozwala na autonomiczne sterowanie pracą silnika, poczynając od rozruchu [8-10, 21, 22] (w tym także dla układu z dławikiem rozruchowym), przez odpowiednie sterowanie wyłącznikami w polu $6 \mathrm{kV}$ rozdzielni zasilającej silnik oraz mostkiem tyrystorowym w obwodzie wzbudzenia, pracę synchroniczną z możliwością utrzymywania zadanej wartości prądu wzbudzenia lub mocy biernej, procedury forsowania prądu wzbudzenia, po proces wyłączenia technologicznego lub awaryjnego $\mathrm{z}$ rozładowaniem energii uzwojenia wzbudzenia [10]. Dodatkowo urządzenie może być włączone do nadrzędnego systemu kompensacji mocy biernej, realizując bezstopniową, nadążną regulację mocy biernej w trakcie pracy synchronicznej silnika [6].

Zastosowanie urządzenia do sterowania napędem wentylatora głównego przewietrzania kopalni wprowadza ostre kryteria dotyczące pracy napędu. Przepisy górnicze wymagają, aby w każdym szybie wydechowym oprócz czynnego wentylatora obecny był wentylator rezerwowy, którego uruchomienie możliwe jest w ciągu 10 minut [19]. Awaria wentylatora głównego i nieudany rozruch wentylatora rezerwowego stwarzają poważne zagrożenie dla zdrowia i życia załogi, a przerwa trwająca co najmniej 20 minut skutkuje wstrzymaniem robót i wyprowadzeniem pracowników w kierunku szybów wdechowych lub na powierzchnię [19]. Ważne jest więc ustalenie właściwych

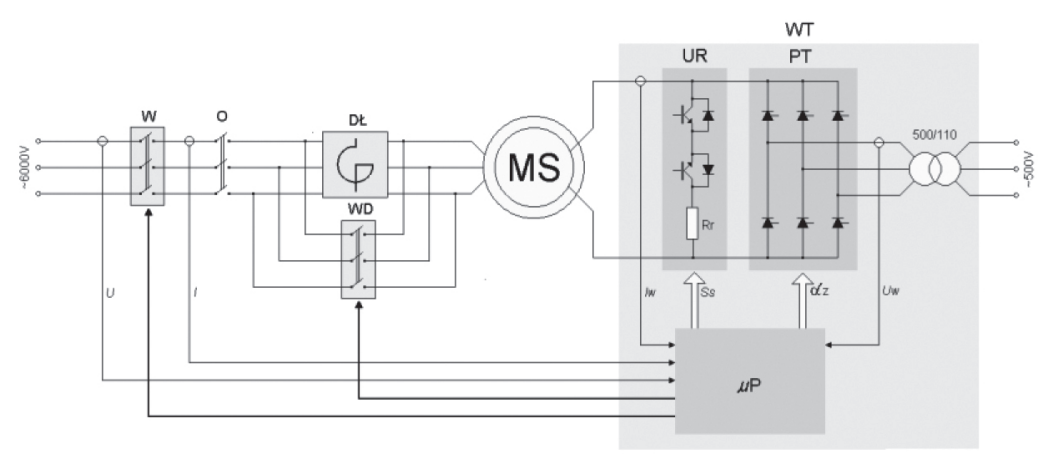

Rys. 4. Schemat układu sterowania silnika: MS - silnik synchroniczny, WT - wzbudnica tyrystorowa, $\mu P$ - system mikroprocesorowy, PT - prostownik tyrystorowy, UR - układ rozruchowy, $W$ - wyłacznik, $O$ - odtacznik, WD - wytacznik dtawika, DE - dtawik rozruchowy 
parametrów rozruchu oraz ograniczenia zakresu regulacji prądu wzbudzenia w trakcie pracy synchronicznej. Pomocne w tym celu mogą być procedury umożliwiające monitorowanie i diagnostykę pracy napędu, zarówno w trybie online, jak i z możliwością przeglądania danych archiwalnych, co ma szczególne znaczenie podczas analizy ewentualnych, niespodziewanych stanów awaryjnych.

\section{REJESTRACJA I MONITOROWANIE STANU URZADZENIA}

System mikroprocesorowy urządzenia rejestruje wartości pomiarowe mocy czynnej i biernej, napięcia zasilania, prądu stojana i prądu wzbudzenia. Rejestrowane są także wszystkie zmiany stanu lub trybu pracy, sterowanie łącznikami pola zasilającego w rozdzielni $6 \mathrm{kV}$, realizacja procedur dodatkowych (np. forsowanie prądu wzbudzenia przy zapadzie napięcia zasilania [7, 13]), wystąpienie zdarzeń alarmowych lub awaryjnych wykrytych przez algorytmy programowe systemu mikroprocesorowego lub zewnętrzne urządzenia zabezpieczające. Rejestrowane informacje przechowywane są w pamięci nieulotnej i moga być wykorzystane do analizy pracy napędu i diagnozowania ewentualnych nieprawidłowości. Możliwe jest także przesyłanie rejestrowanych informacji w czasie rzeczywistym do urządzenia zewnętrznego za pomoca dostępnych interfejsów komunikacyjnych.

Jednym $\mathrm{z}$ elementów interfejsu HMI urządzenia jest ekran LCD pozwalający m.in. na monitorowanie stanu pracy napędu. Wyświetlane są informacje o stanie aktualnym, ostrzeżenia alarmowe i awaryjne czy wykresy przebiegów czasowych rejestrowanych wielkości pomiarowych. Na rysunku 5 przedstawiono przykładowe informacje wyświetlane na ekranie urządzenia.

Mikroprocesorowy blok zasilania wzbudzenia wyposażony jest w zestaw interfejsów komunikacyjnych współpracujących z oprogramowaniem diagnostyczno-serwisowym lub zewnętrznymi systemami nadzorującymi. Dostępny jest interfejs MODBUS ASCII i RTU [17] w standardzie RS-485, łącze USB [16] oraz interfejs sieci Ethernet realizujący łączność z wykorzystaniem protokołu TCP/IP [20] z systemem autoryzacji użytkownika i możliwością filtrowania adresów IP umożliwiających ustanowienie połączenia. Przy łączności Ethernetowej możliwa jest praca w trybie klienta lub serwera. Dodatkowo w oprogramowaniu urządzenia zaimplementowano serwer HTTP [14] umożliwiający dostęp do podstawowych informacji z wykorzystaniem przeglądarki internetowej z obsługą JavaScript.

$\mathrm{Na}$ rysunku 6 przedstawiono przykładowe strony generowane przez serwer HTTP wbudowany w oprogramowanie systemu mikroprocesorowego. Zawartość stron jest automatycznie odświeżana w przeglądarce internetowej z okresem $10 \mathrm{~s}$.

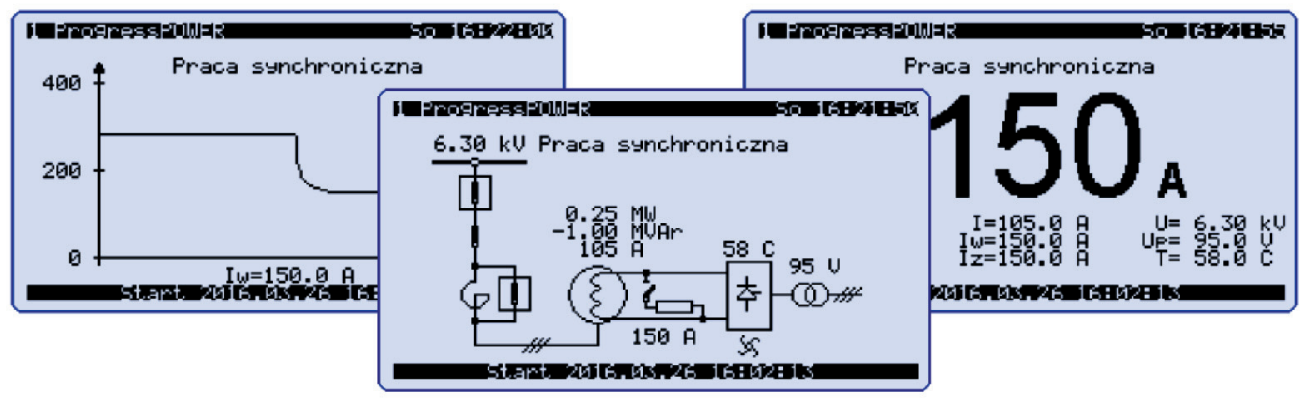

Rys. 5. Monitorowanie pracy napędu na ekranie LCD urządzenia

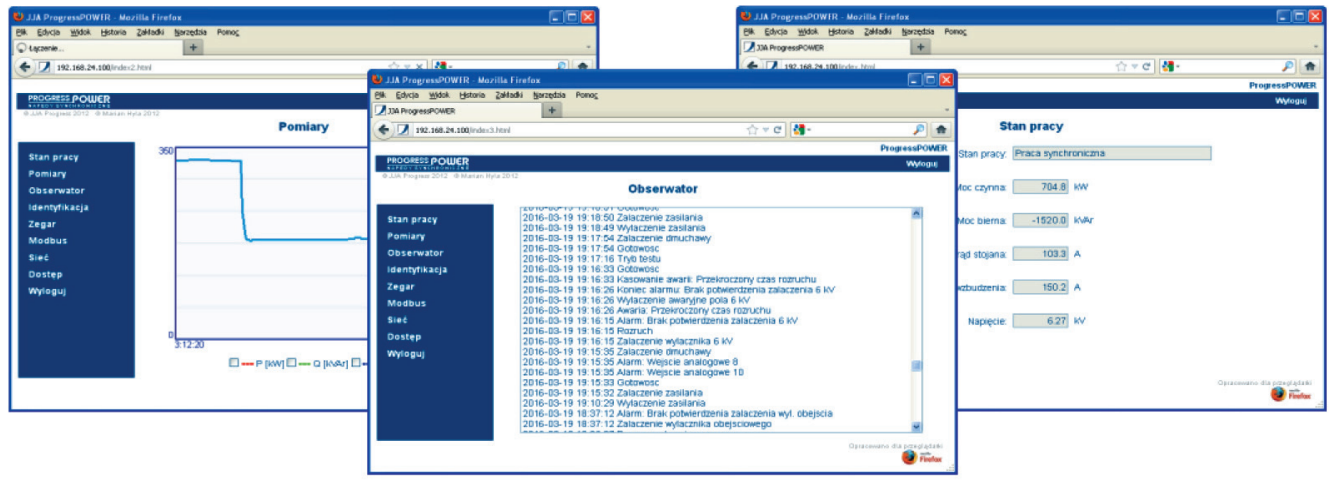

Rys. 6. Monitorowanie pracy napędu z wykorzystaniem przegladarki internetowej 


\section{OPROGRAMOWANIE DIAGNOSTYCZNE}

W celu szczegółowej analizy pracy napędu z mikroprocesorowym blokiem zasilania wzbudzenia opracowano oprogramowanie diagnostyczno-serwisowe dla systemu Windows. Oprogramowanie umożliwia monitorowanie i sterowanie praca urządzenia poprzez interfejs RS-485, USB lub połączenie TCP/IP w sieci Ethernet.

Na rysunku 7 przedstawiono wygląd interfejsu oprogramowania dedykowanego do obsługi diagnostyczno-serwisowej.

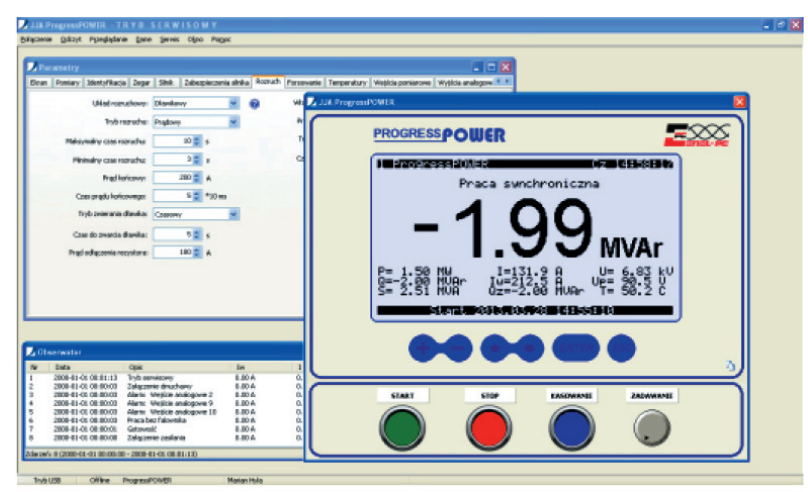

Rys. 7. Oprogramowanie diagnostyczno-serwisowe

Jedną z funkcji diagnostycznych jest możliwość pobrania z pamięci nieulotnej systemu mikroprocesorowego zarejestrowanych zdarzeń związanych z pracą układu napędowego. Rejestracja tego typu informacji w urządzeniu i możliwość przeglądania ich w dowolnym czasie przydatna jest do analizy zachowania się napędu w przypadku nietypowych i nieprzewidzianych zdarzeń związanych $\mathrm{z}$ pracą urządzenia napędzanego lub systemu zasilającego.

Na rysunku 8 przedstawiono przykładową sekwencję zdarzeń odczytaną z systemu mikroprocesorowego. Oprogramowanie diagnostyczne pozwala na przeglądanie, wyszukiwanie, sortowanie i filtrowanie odczytanych informacji.

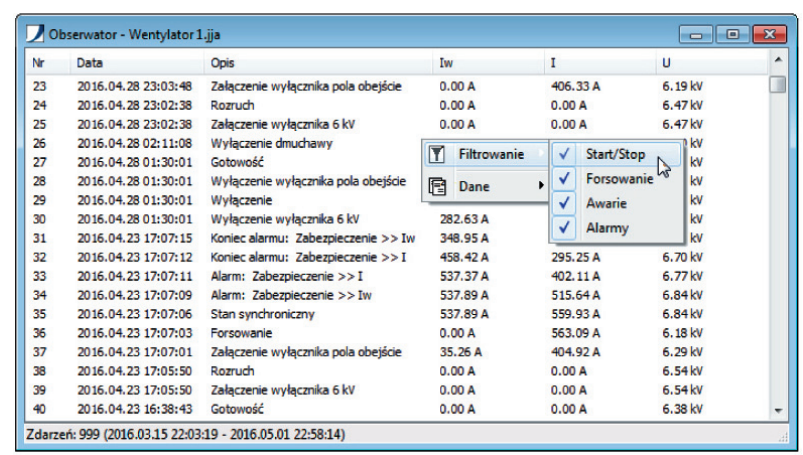

\section{Rys. 8. Analiza zdarzeń zarejestrowanych przez system mikroprocesorowy}

Oprogramowanie diagnostyczne umożliwia odczyt rejestrowanych przebiegów czasowych wielkości pomiarowych oraz synchronizację pomiarów z systemem rejestracji zdarzeń w jednym oknie. Na rysunku 9 przedstawiono okno analizy stanu pracy. Nietypowy przebieg prądu wzbudzenia w początkowej fazie rozruchu silnika wynika z zastosowanego jednokierunkowego przetwornika pomiarowego prądu typu LEM oraz z okresu próbkowania sygnału przez procedurę pomiarową systemu mikroprocesorowego.

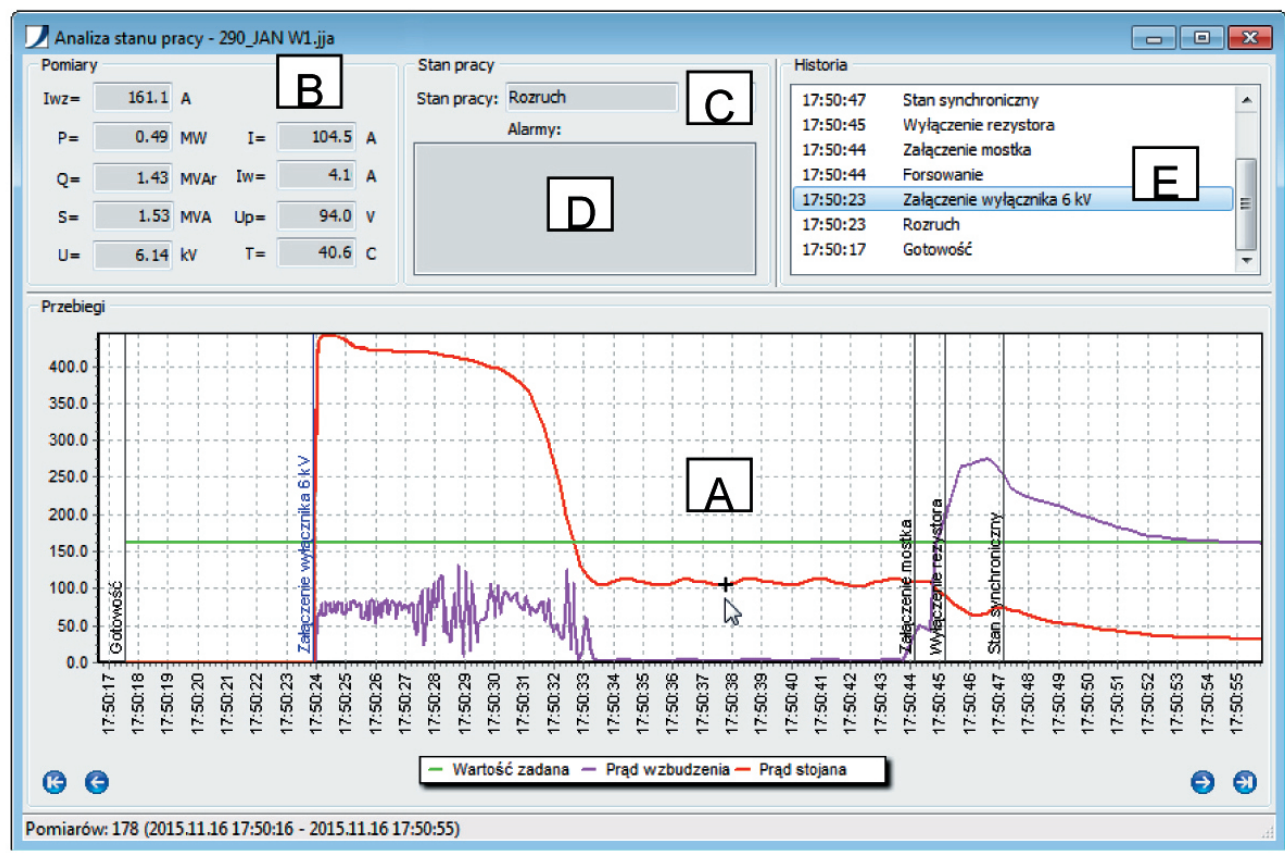

Rys. 9. Okno diagnostyki pracy napędu 
W dolnej części okna analizy stanu pracy (obszar A) wyświetlane są przebiegi pomiarowe $\mathrm{z}$ wybranego przedziału czasowego z nałożoną informacją z systemu rejestracji zdarzeń. Umieszczenie kursora myszy w dowolnej pozycji wykresu skutkuje wyświetleniem w obszarze B wartości pomiarowych ze wskazanej chwili czasowej, opisem stanu pracy napędu w obszarze $\mathrm{C}$ oraz wyświetleniem aktywnych w tym czasie alarmów i awarii w obszarze D. Obszar E okna umożliwia wybór zdarzenia z listy zarejestrowanych zdarzeń. Wybór zdarzenia z listy powoduje automatyczne wyskalowanie i przesunięcie wykresu z obszaru A do odpowiedniej chwili czasowej.

Analityczne wyznaczenie obszaru pracy silnika synchronicznego ze względu na dopuszczalną wartość kąta mocy wymaga znajomości reaktancji synchronicznych $X_{d}$ i $X_{q}$. Pomiarowe wyznaczenie krzywych Mordeya umożliwia weryfikację wartości przyjętych do obliczeń oraz ewentualną korektę ograniczenia związanego z minimalną dopuszczalną wartością prądu wzbudzenia.

Na rysunku 10 przedstawiono okno oprogramowania diagnostycznego umożliwiające wykreślenie krzywych $\mathrm{V}$ na podstawie serii pomiarów zarejestrowanych w stanie pracy synchronicznej. Oprogramowanie umożliwia wybór przedziału mocy czynnej dla każdej z wykreślanych krzywych oraz dopasowanie liczby próbek dla wyznaczania wykreślanych wartości metodą średniej kroczącej.

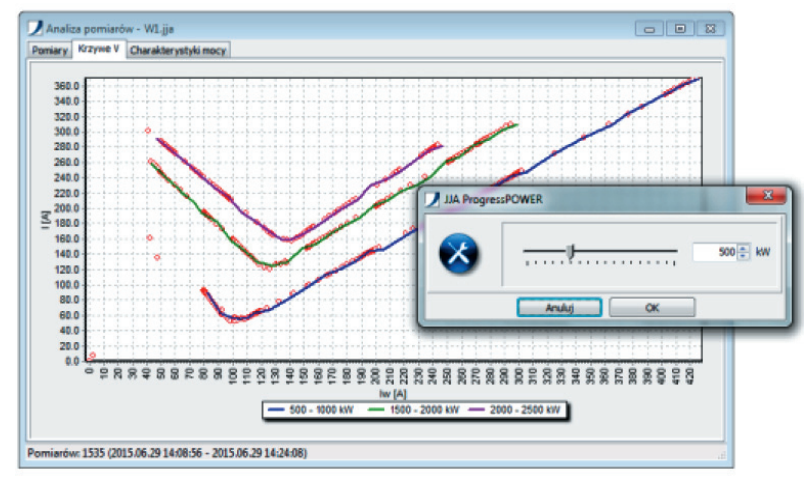

Rys. 10. Wyznaczanie krzywych Mordeya na podstawie pomiarów $w$ stanie synchronicznym

\section{PODSUMOWANIE}

Przedstawiony mikroprocesorowy blok zasilania wzbudzenia silników synchronicznych wraz z oprogramowaniem diagnostyczno-serwisowym jest roz- wiązaniem autorskim, jednym $\mathrm{z}$ najnowocześniejszych na rynku.

Zastosowanie zaprezentowanego urządzenia z mikroprocesorowym układem sterowania pozwala na zautomatyzowanie procesu rozruchu silnika synchronicznego, uproszczenie obsługi i zmniejszenie awaryjności napędu. Umożliwia wykorzystanie urządzenia w układach automatycznego załączania napędu rezerwowego w przypadku awarii układu podstawowego.

Wbudowane interfejsy komunikacyjne pozwalają na zdalne sterowanie i monitorowanie pracy napędu. Możliwość wykorzystania silnika z mikroprocesorowym blokiem zasilania wzbudzenia jako regulowanego źródła mocy biernej w nadążnym układzie kompensacji pozwala na prostą integrację urządzenia z zakładowymi systemami zapewnienia jakości energii elektrycznej.

Oprogramowanie diagnostyczne $\mathrm{z}$ rejestracją parametrów pracy umożliwia dogłębną analizę zachowania się układu napędowego. Wykorzystanie przedstawionego oprogramowania w procesie rozruchu technologicznego podczas wdrażania urządzenia, pozwala na dobór i diagnozę parametrów rozruchu [5, 8-10] oraz nastaw regulatorów i ograniczeń zapewniających prawidłową pracę układu napędowego.

Kilkadziesiąt wdrożeń zrealizowanych przez firmę JJA Progress przy współudziale autora w układach napędowych z silnikami synchronicznymi dużej mocy, głównie wentylatorów przewietrzania kopalń głębinowych oraz bezawaryjna praca eksploatowanych urządzeń potwierdza skuteczność zastosowanych rozwiązań oraz przydatność opracowanych narzędzi diagnostycznych.

\section{Literatura}

[1] Al-Hamrani M.M., Von Jouanne A., Wallace A.: Power factor correction in industrial facilities using adaptive excitation control of synchronous machines, Conference Record of the 2002 Annual Pulp and Paper Industry Technical Conference, Toronto, Ontario, Canada 2002: 148-154.

[2] Bajorek Z.: Teoria maszyn elektrycznych, Wydawnictwo Politechniki Rzeszowskiej, Rzeszów 1987.

[3] Campeanu A., Enache S., Vlad I., Liuba G., Augustinov L., Cautil I.: Simulation of asynchronous operation in high power salient pole synchronous machines, XXth International Conference on Electrical Machines (ICEM), Marseille 2012: 1823-1828.

[4] Colak I., Bayindir R., Bay O.F.: Reactive power compensation using a fuzzy logic controlled synchronous motor, „Energy Conversion and Management" 2003, 44: 2189-2204.

[5] Dokumentacja techniczno-ruchowa wzbudnicy Progress POWER. ENEL-PC, Gliwice 2011.

[6] Hyla M.: Automatic compensation of reactive power with a system for monitoring a $6 \mathrm{kV}$ electrical power grid in mine, „Mining - Informatics, Automation and Electrical Engineering" 2015, 2: 5-10. 
[7] Hyla M.: Impact of voltage dips on the operations of a high-power synchronous motor with a reactive power controller, „Mining - Informatics, Automation and Electrical Engineering" 2016, 2: 5-13.

[8] Hyla M.: Power supply unit for the excitation of a synchronous motor with a reactive power regulator, „Mining - Informatics, Automation and Electrical Engineering" 2015, 1: 17-21.

[9] Hyla M.: Rozruch silnika synchronicznego z mikroprocesorowym blokiem zasilania wzbudzenia, „Przegląd Elektrotechniczny" 2017, 4: 177-184.

[10] Hyla M.: Wybrane aspekty sterowania tyrystorowa wzbudnica silnika synchronicznego, V Ogólnopolska Konferencja Naukowa Modelowanie i Symulacja MIS-5, Kościelisko 2008, s. $345-348$.

[11] Igbinovia F. O., Fandi G., Švec J., Müller Z., Tlusty J.: Comparative review of reactive power compensation technologies, 16th International Scientific Conference on Electric Power Engineering (EPE), Kouty nad Desnou, 2015, s. 2-7.

[12] Kaczmarek T., Zawirski K.: Układy napędowe z silnikiem synchronicznym, Wydawnictwo Politechniki Poznańskiej, Poznań 2000.

[13] Kay J.A., Paes R. H, Seggewiss J.G., Ellis R.G.: Methods for the control of large medium-voltage motors: application considerations and guidelines, IEEE Transactions on Industry Applications 2000, 36, 6: 1688-1696.

[14] Krishnamurthy B., Rexford J.: Web protocols and practice: HTTP/1.1, networking protocols, caching, and traffic measurement, Addison-Wesley Professional, Boston 2001.

[15] Latek W.: Teoria maszyn elektrycznych, WNT, Warszawa 1987.
[16] Mielczarek W.: USB. Uniwersalny interfejs szeregowy, Wydawnictwo Helion, Gliwice 2005.

[17] Modicon MODBUS Protocol Reference Guide. Modicon Inc., USA 1993.

[18] Plamitzer A.: Maszyny elektryczne, WNT, Warszawa 1986.

[19] Rozporzadzenie Ministra Gospodarki z dnia 28 czerwca 2002 r. $w$ sprawie bezpieczeństwa $i$ higieny pracy, prowadzenia ruchu oraz specjalistycznego zabezpieczenia przeciwpożarowego w podziemnych zakładach górniczych (Dz.U. z 2002 r., nr 139, poz. 1169 oraz z 2006 r., nr 124, poz. 863 oraz z 2010 r., nr 126, poz. 855).

[20] Siyan K.S., Parker T.: TCP/IP. Ksiega eksperta, Wydawnictwo Helion, Gliwice 2002.

[21] Zalas P., Zawilak J.: Łagodzenie oraz skrócenie czasu procesu synchronizacji silników synchronicznych, „Elektrotechnika i Elektronika” 2006, 25, 2: 216-220.

[22] Zalas P., Zawilak J.: Wpływ układu sterowania prądem wzbudzenia na proces synchronizacji silnika synchronicznego, „Maszyny Elektryczne - Zeszyty Problemowe” 2006, 75: 83-88.

dr inz. MARIAN HYLA

Wydziat Elektryczny

Politechnika Ślaska

ul. B. Krzywoustego 2, 44-100 Gliwice marian.hyla@polsl.pl 